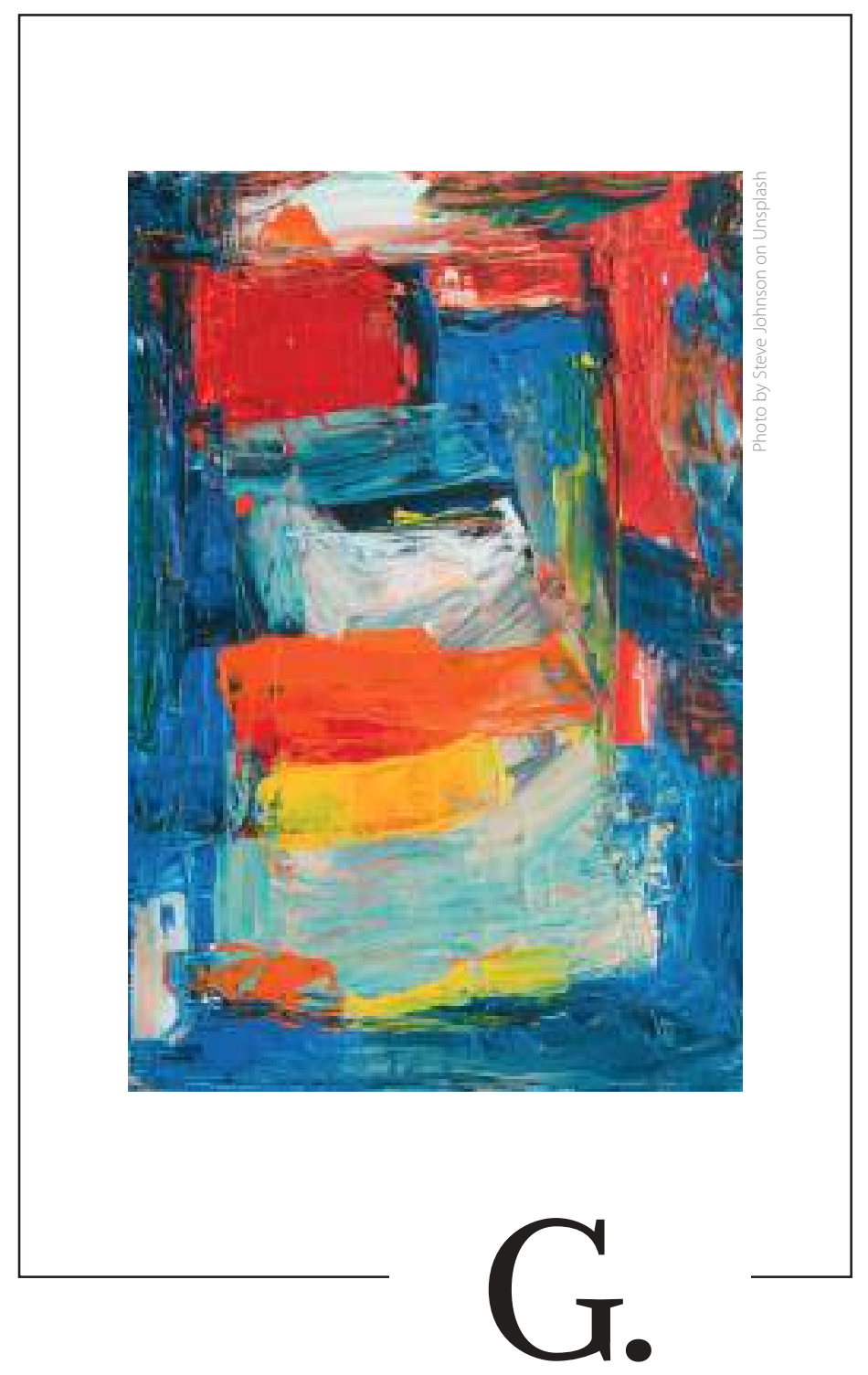

GALERÍA 


\section{ENTRE LO CÁLIDO Y LO VISCERAL}

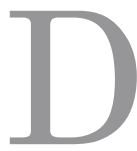

esde la exposición en quioscos, impreso en papel periódico y realizado por un sinfín de colaboradores, hasta las páginas de descarga gratuita de los zines más underground de la web, el cómic nos ha acompañado y se ha acoplado a nuestro estilo de vida a lo largo del siglo xx. Tanto en presentaciones que han cubierto los espacios de entretenimiento publicitario como en la realización de trabajos cada vez más personales y creativos; encontramos así un género inmensurable que navega por igual en las corrientes pop de esta era o en los escondrijos más íntimos del trabajo de autor.

Conocido como el noveno arte, el cómic cuenta en su haber con una diversa malla de subgéneros, tales como la aventura, el erotismo, la ciencia ficción, las historias bélicas; así como una infinidad de líneas y modalidades, que se han ido entrelazando y forjando nuevos híbridos a través de los años. En el ámbito de Lienzo se reconoce su valor, aunque un poco demorado, y es tiempo de hacerle un merecido lugar al cómic.

En el siguiente apartado podremos encontrar dos trabajos peculiarmente distintos, los cuales nos permiten descubrir el nivel de personalización que ha tomado este género a través de los años y cómo se ha convertido en un medio para la exploración personal y una nueva ventana para observar el mundo.

El trabajo de Rocío Diestra, con un tono cálido y juegos inocentes, evidencia temores profundos de su generación. Una voz afable con la que nos identificamos y la constante presencia de una autocrítica millennial reforzada con un humor propio de esta época. El amor romántico, la familia, la juventud, las redes sociales y una atmósfera que le da un papel principal a la cotidianidad.

Por otro lado, tenemos el visceral trabajo de André Sal y Rosas. Un híbrido vehemente entre lo pop y la crudeza. Personajes sacados de una Lima distópica turbia y neón, viñetas dispuestas a punta de cafeína y personajes movidos por puro hedonismo. El deseo carnal, las historias turbulentas y una madrugada eterna son la base de este espacio, donde lo políticamente correcto y las limitaciones del superyó han llegado a morir.

María Gracia Echevarría 


\section{ROCÍO}

\section{DIESTRA}

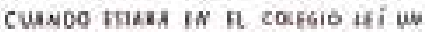

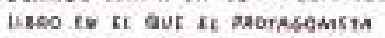

CONZABAA QUF IS HABIA HFCXO UN POATELAPLEAOS A SU AEVELA COAO REGALO DE CUMPLEAÑOK

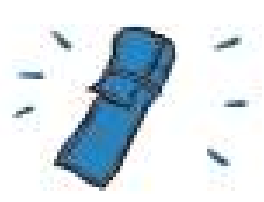

LURESTABLE NENTE, REIATABS, EIE

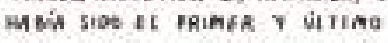
REGHe HESHO A MaNo avf IS

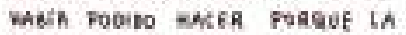
A EUELCA FAMELIO ANTES DE $5 \mathrm{~V}$

SIGUENTE

CAMPLAANOS

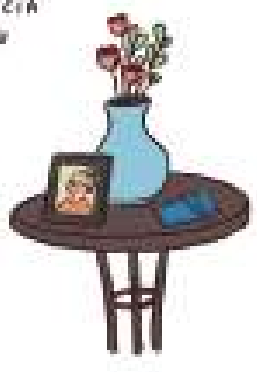

DURANTK LOS SLWENTES SÑOS NO LE Di WW solo retate hecae

A Mavo a Me A Evela

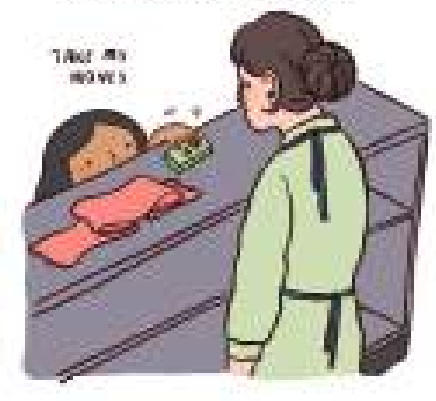

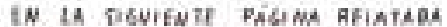
coino SU AEvfHA DeguliosA IE MOSINABA A TOMS DUS REISAT FI

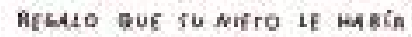
Hecuo col sus Pronis! manot

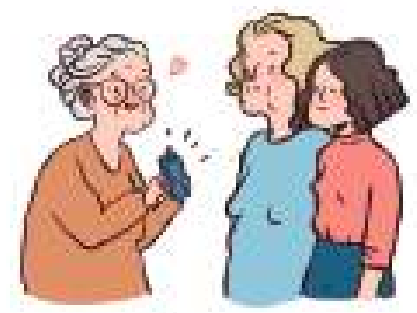

LA urs roais nesó

A mi reven a

IMPNESIONAES JER

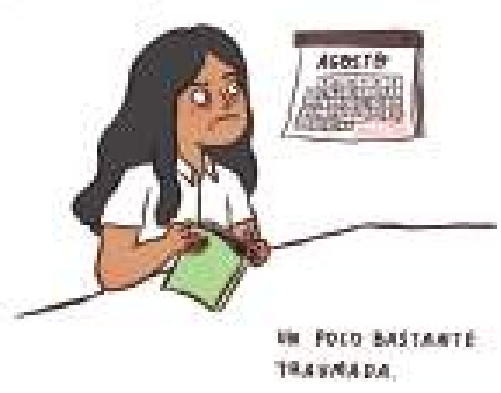

nuห คบเรตอเด.

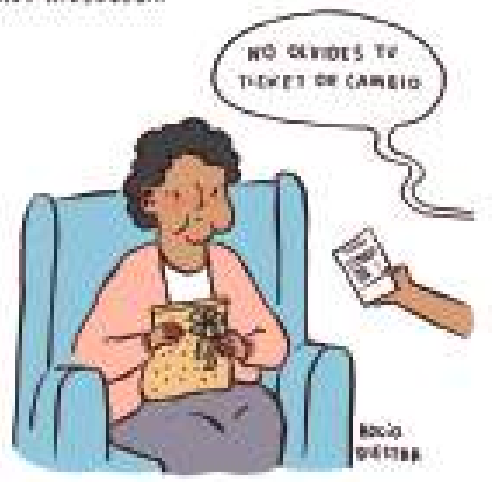




\section{ROCÍO}

\section{DIESTRA}

YO SÉ QUE AL INICIO DIJE QUE NO BUSCABANADA SERIO PERO EN ESTE TIEMPO QUE LLEVAMOS SALIENDO ME HE DADO CVENTA DE QUE SÍ, ME GUSTAS, Y MUCHO. Y QUISIERA SABER SI TÚ SIENTES LO MISMO PARA DAR EL
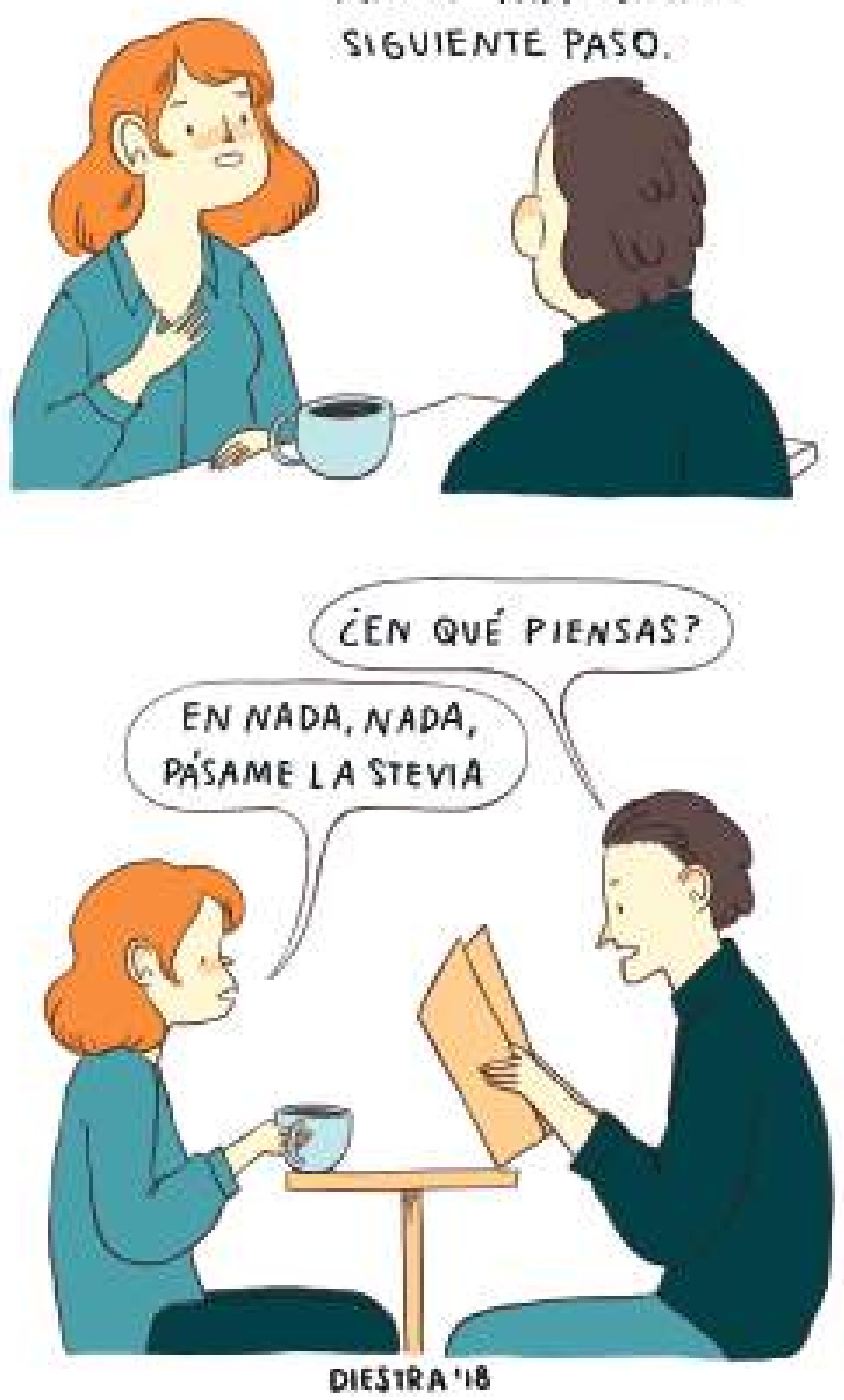


\section{ROCÍO}

\section{DIESTRA}
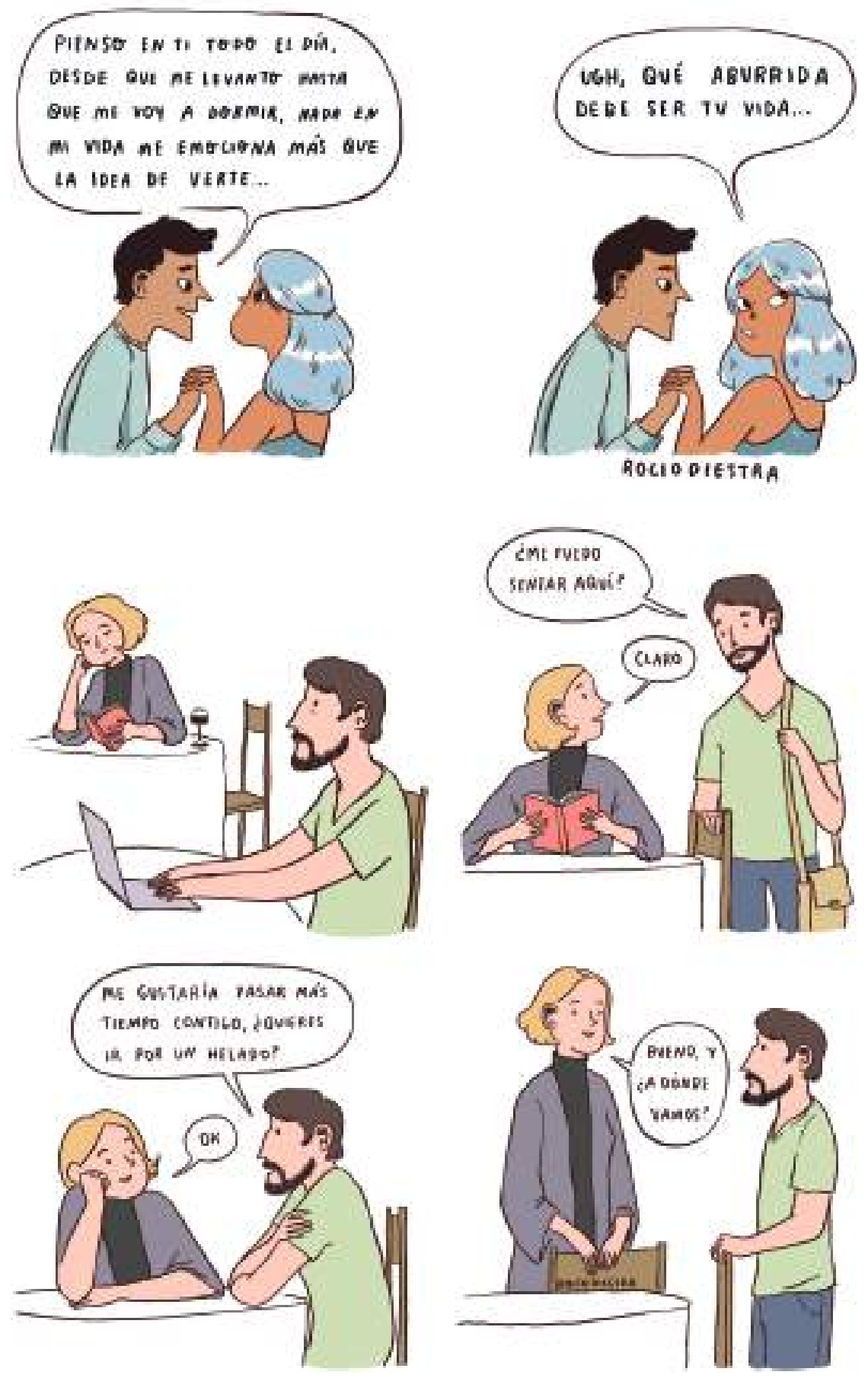


\section{DIESTRA}

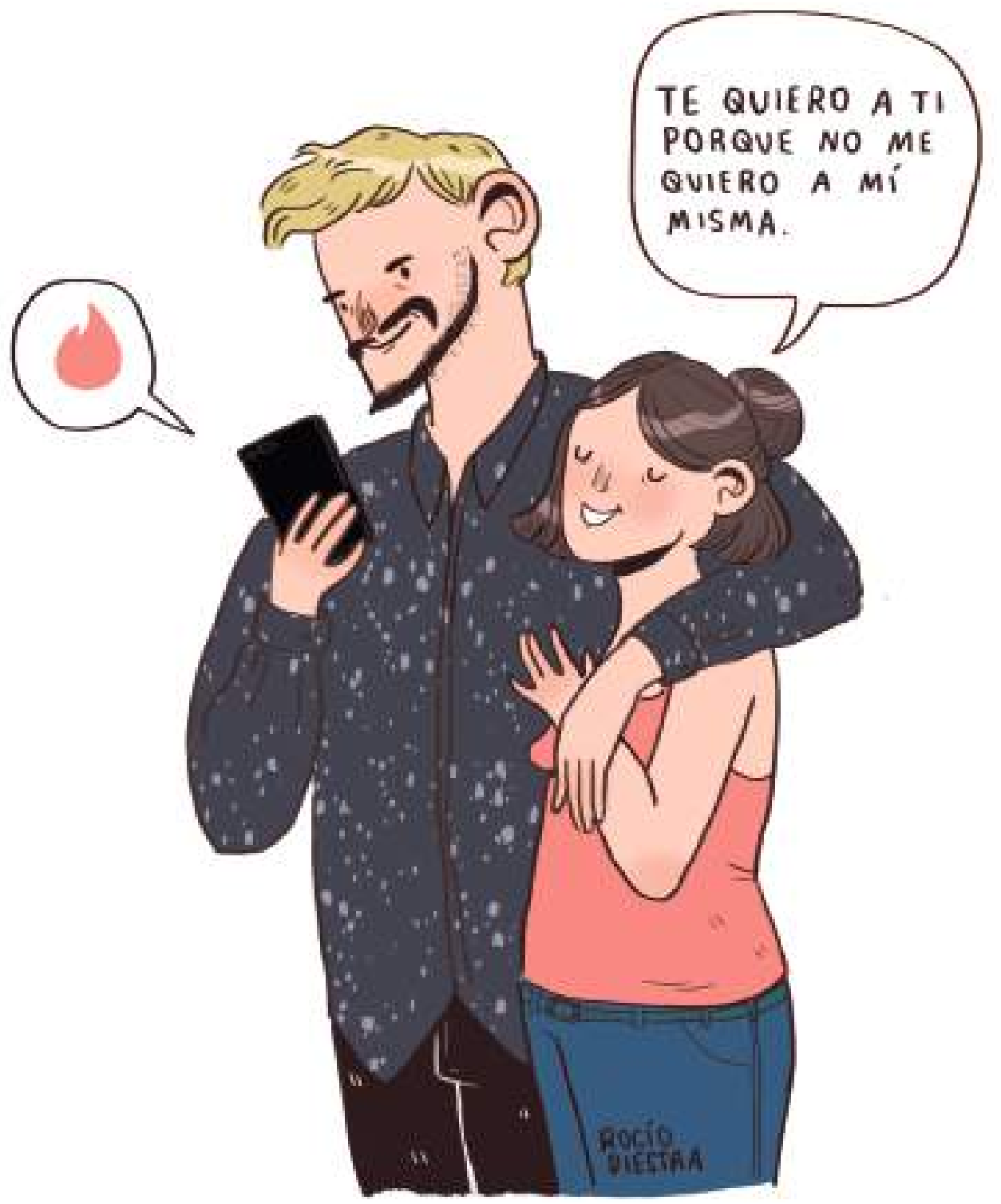




\section{ROCÍO}

\section{DIESTRA}

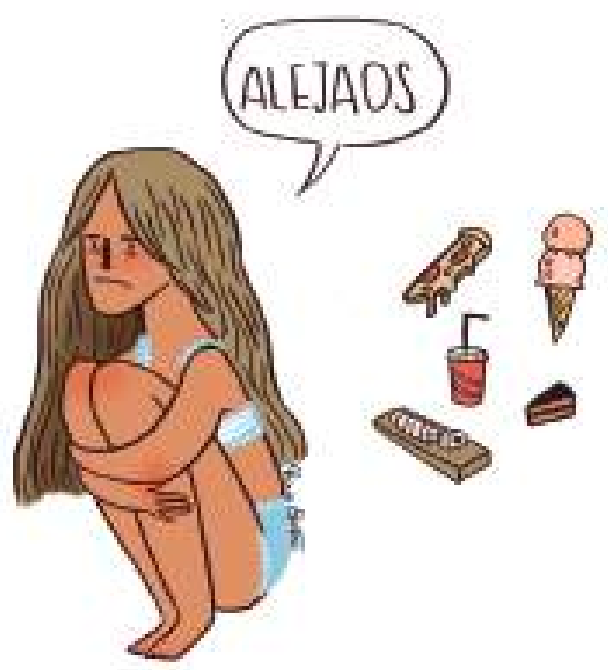

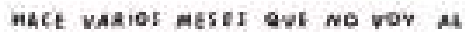
GiMnafio Vin correcateGiA estar QIEN IIANDITA.

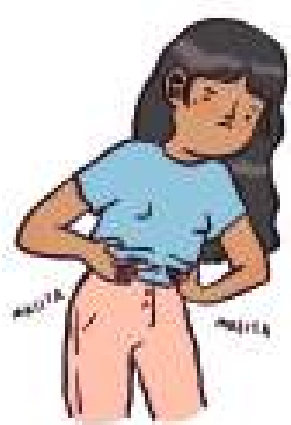

GLANDIIA T SWAVECITA

SIENTO QUE HE ESTDY TRANSTORMANEO.

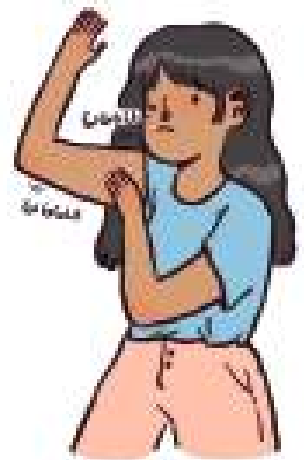

EN UN BLDFISH
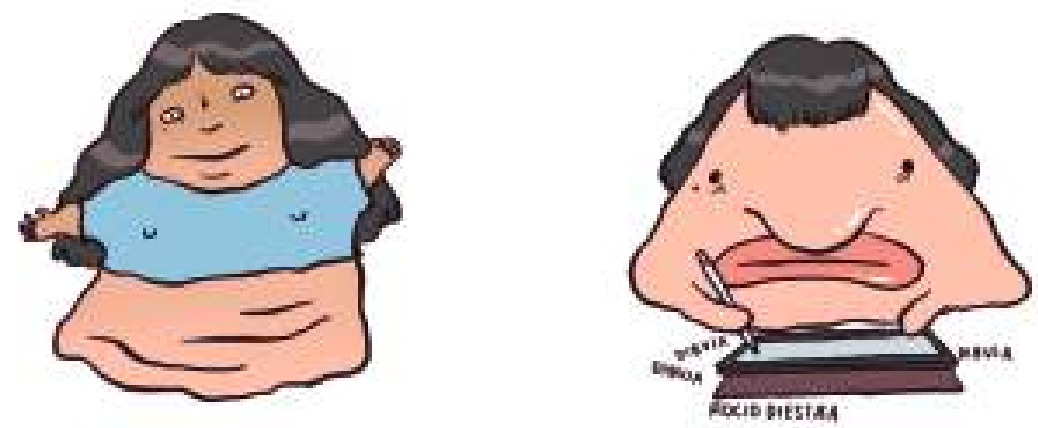


\section{ROCÍO}

\section{DIESTRA}
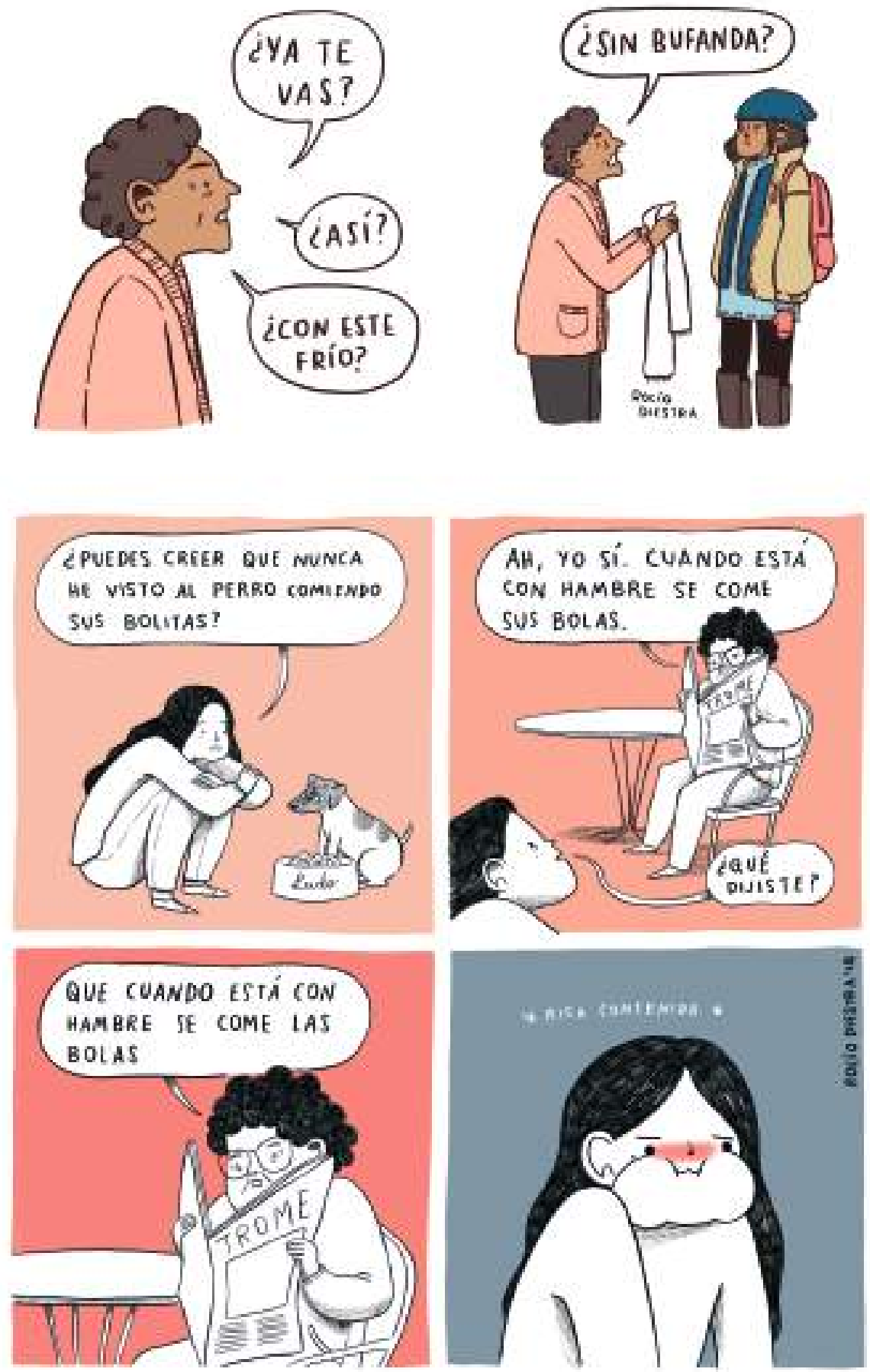


\section{ROCÍO \\ DIESTRA}

POR TI

ME RECORRE

LA JAVIER PRADO

EN HERA PICE

Y EN COMBI
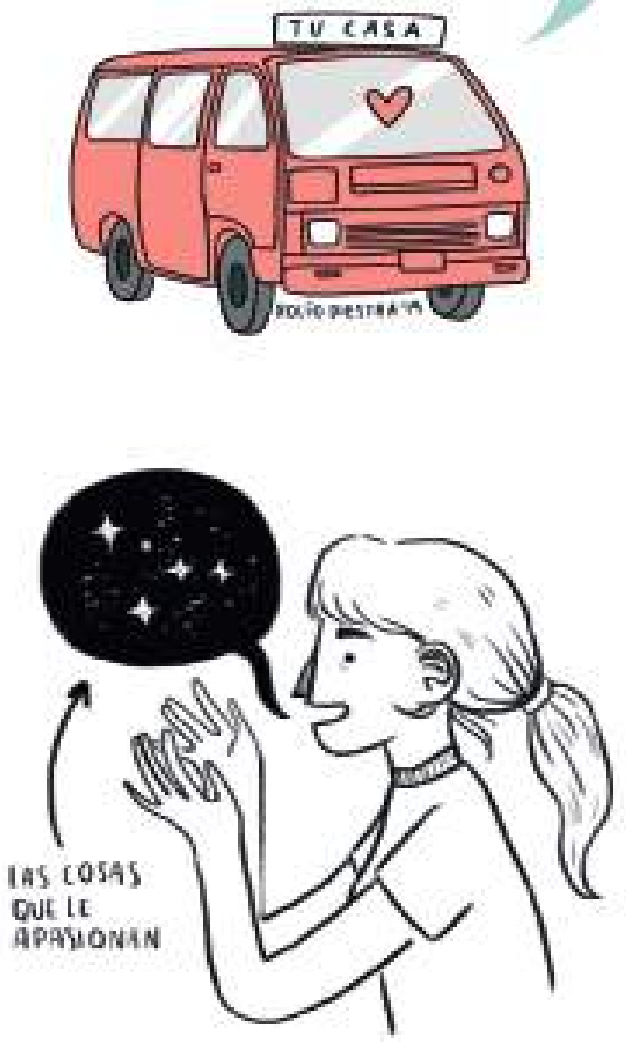
LIENZO, edición extraordinaria / GALERÍA

ROCÍO

\section{DIESTRA}
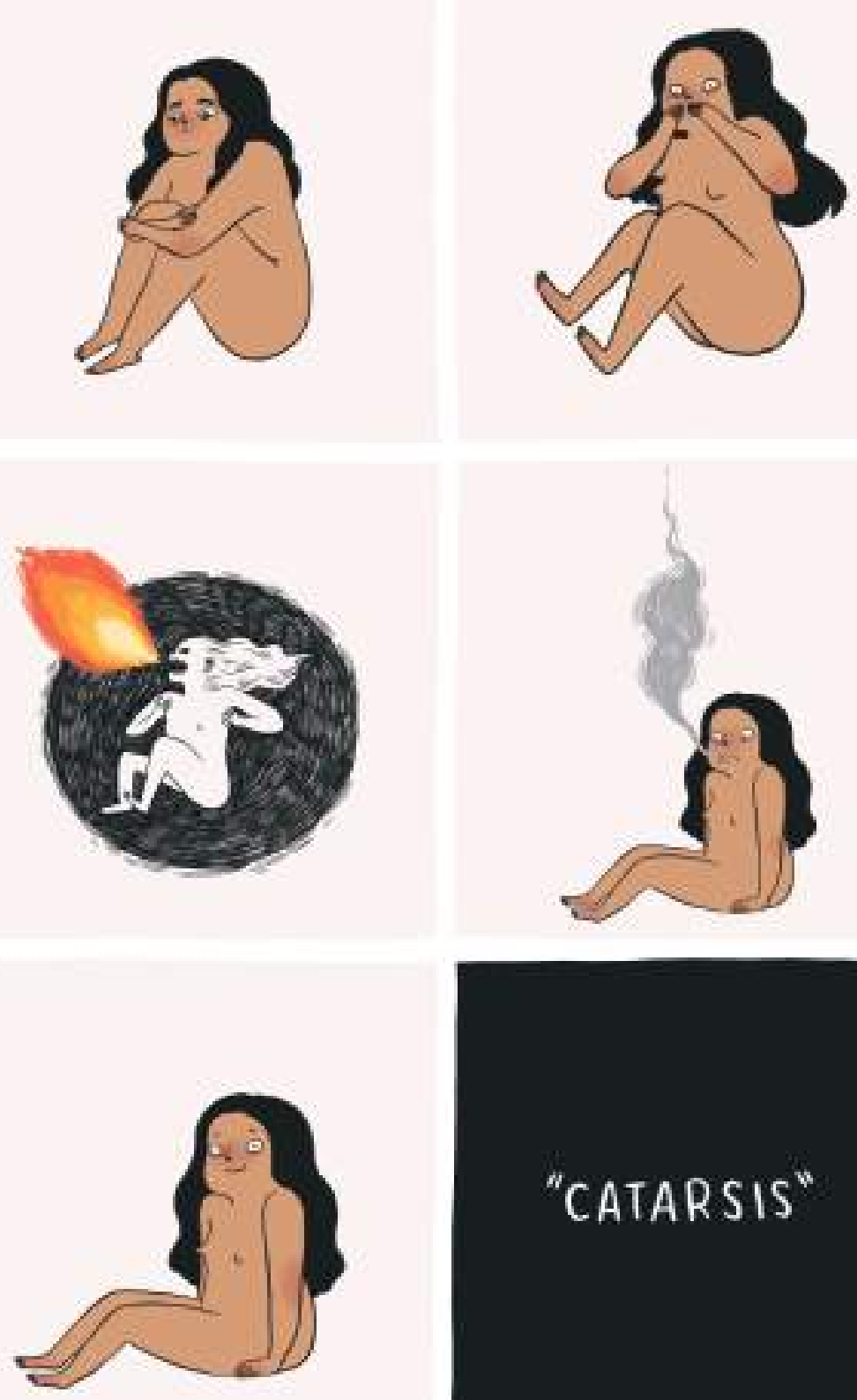
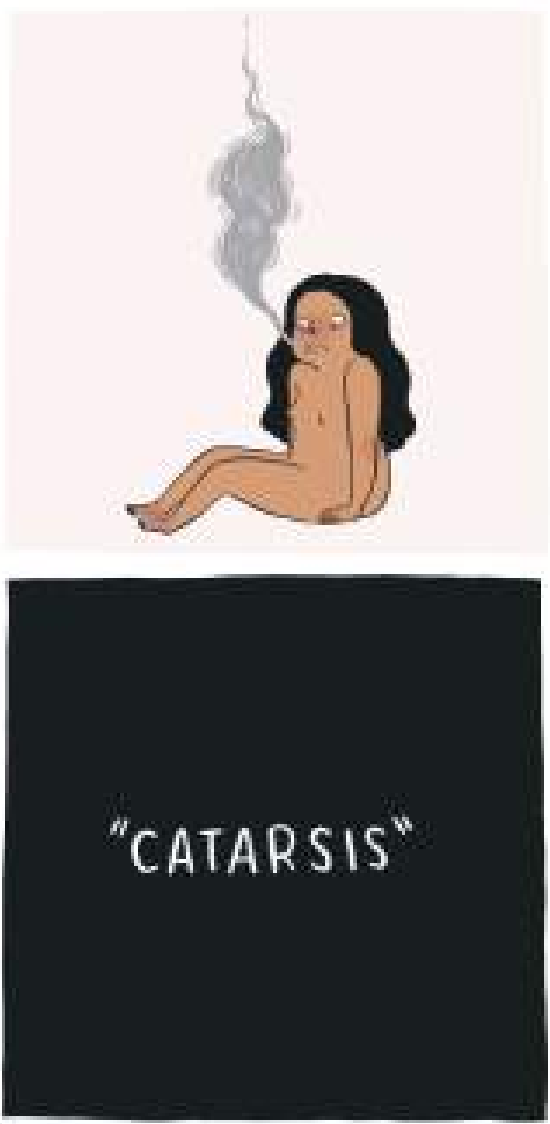


\section{SAL Y ROSAS}

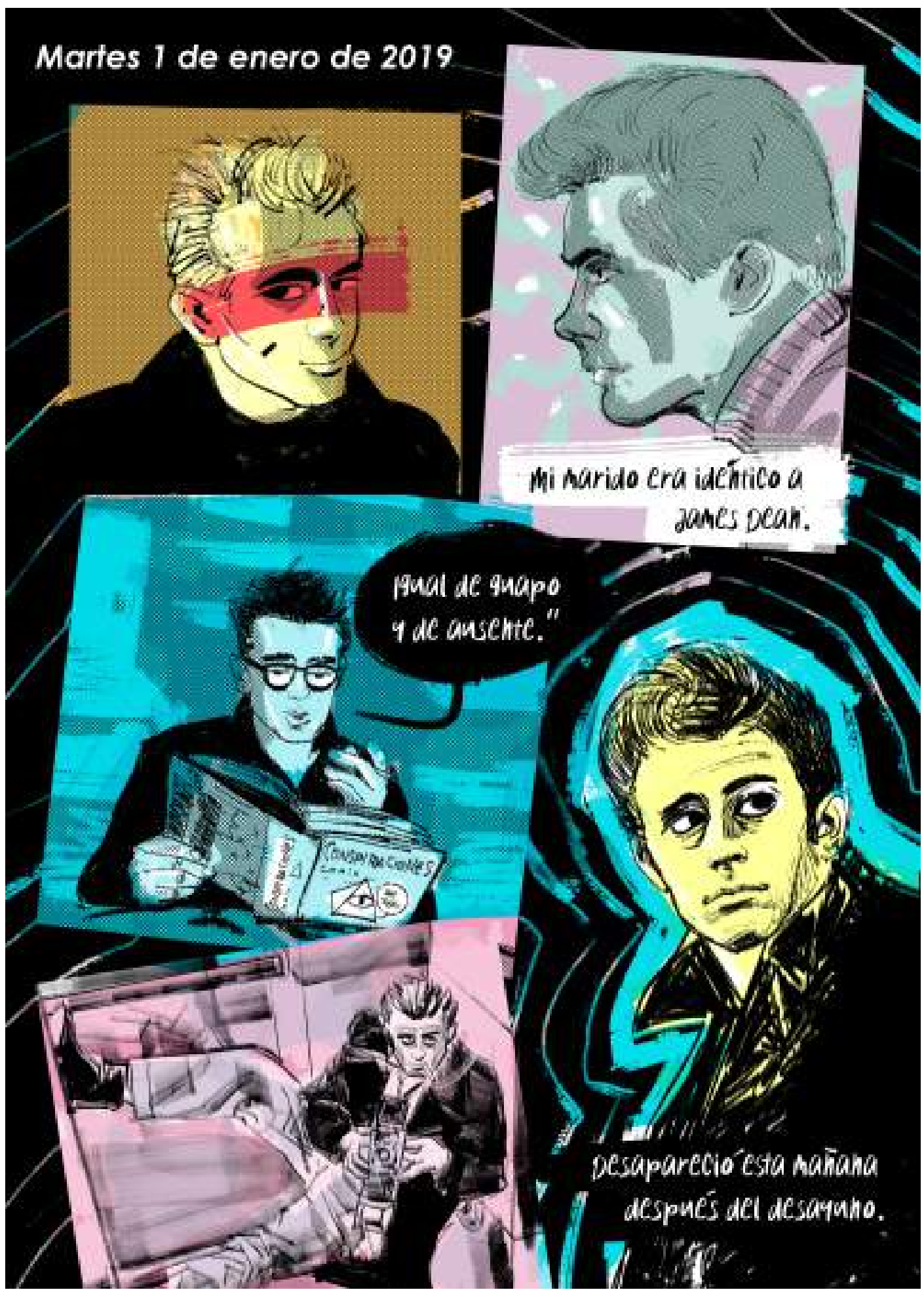




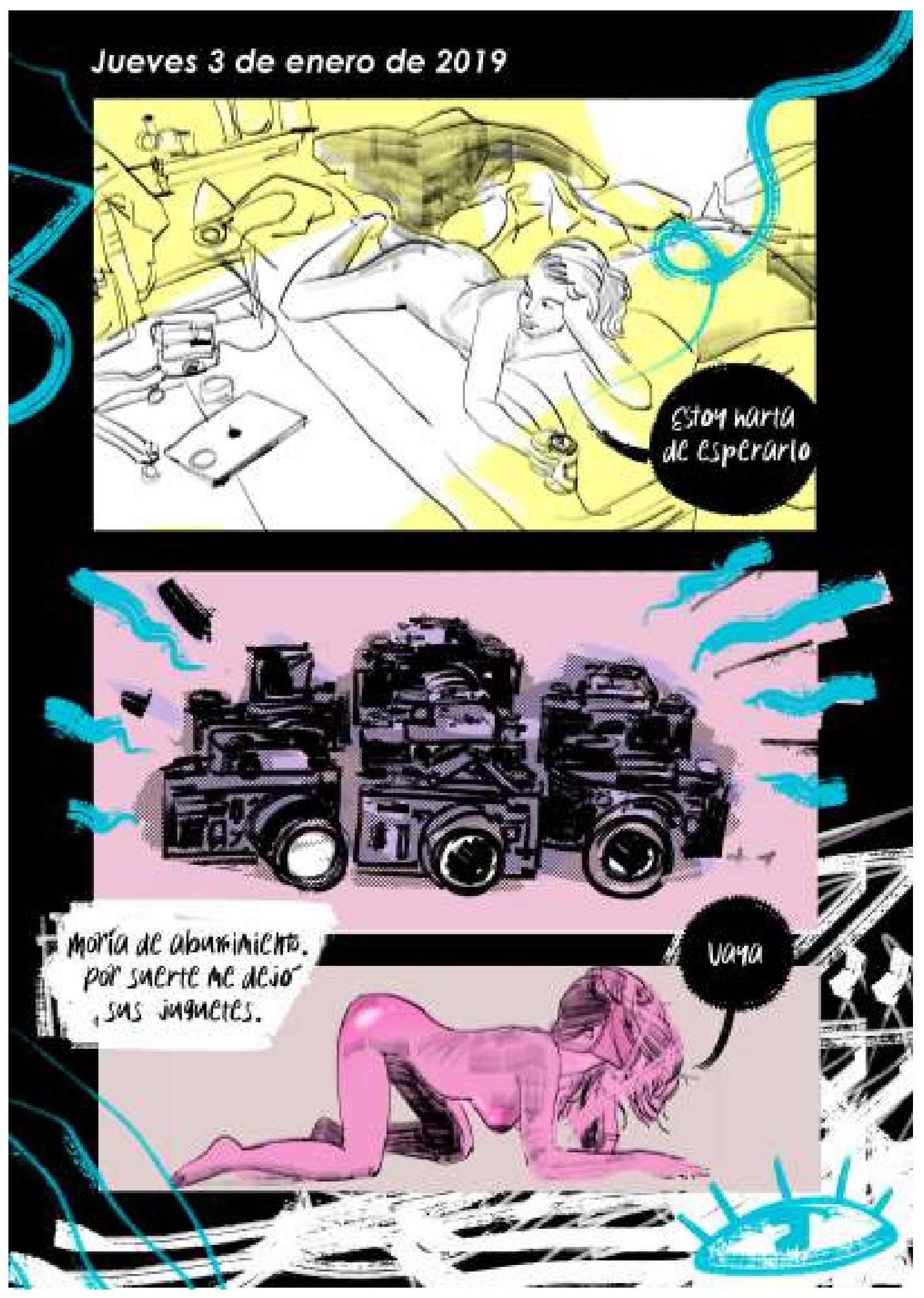




\section{SAL Y ROSAS}

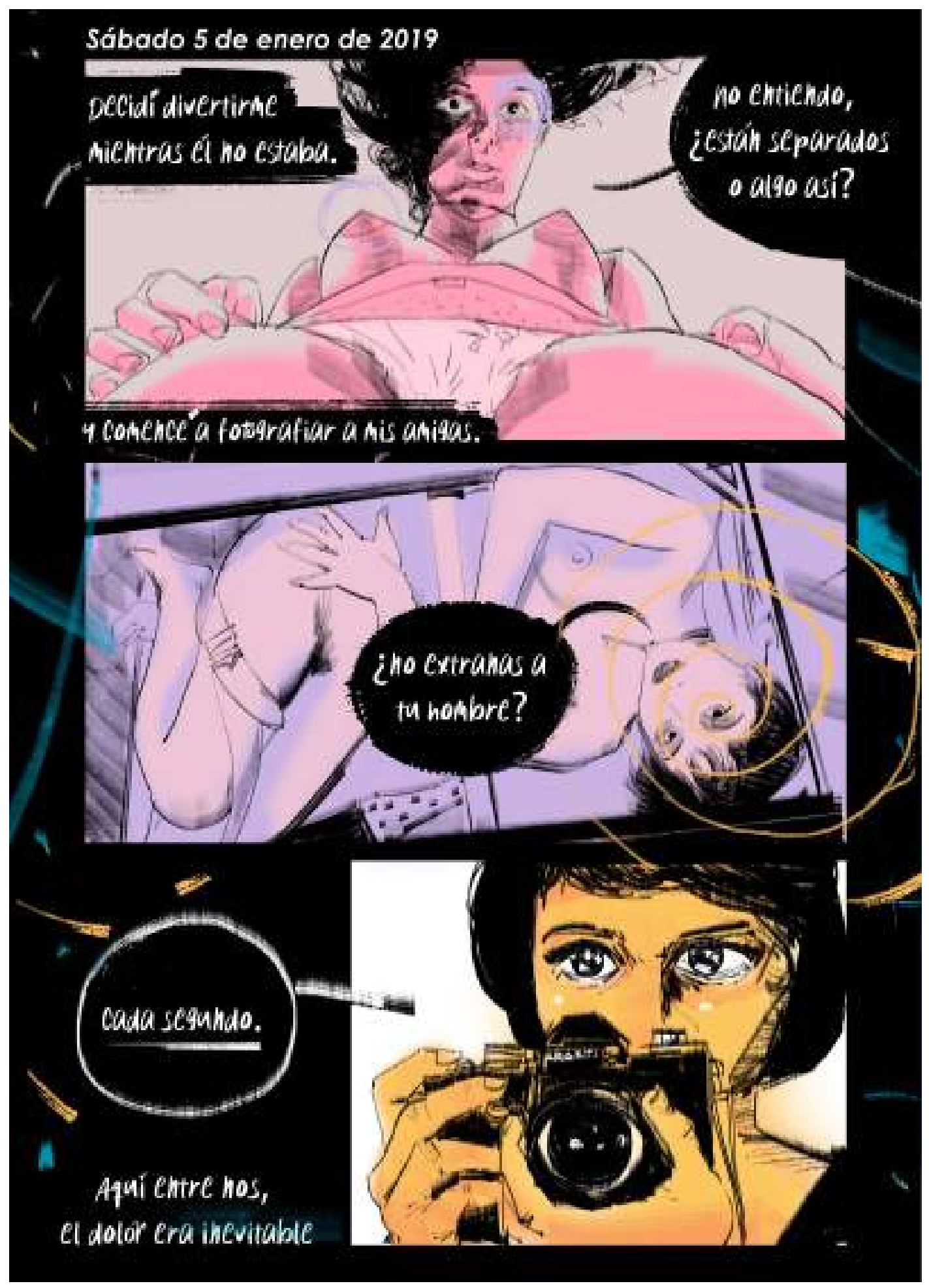




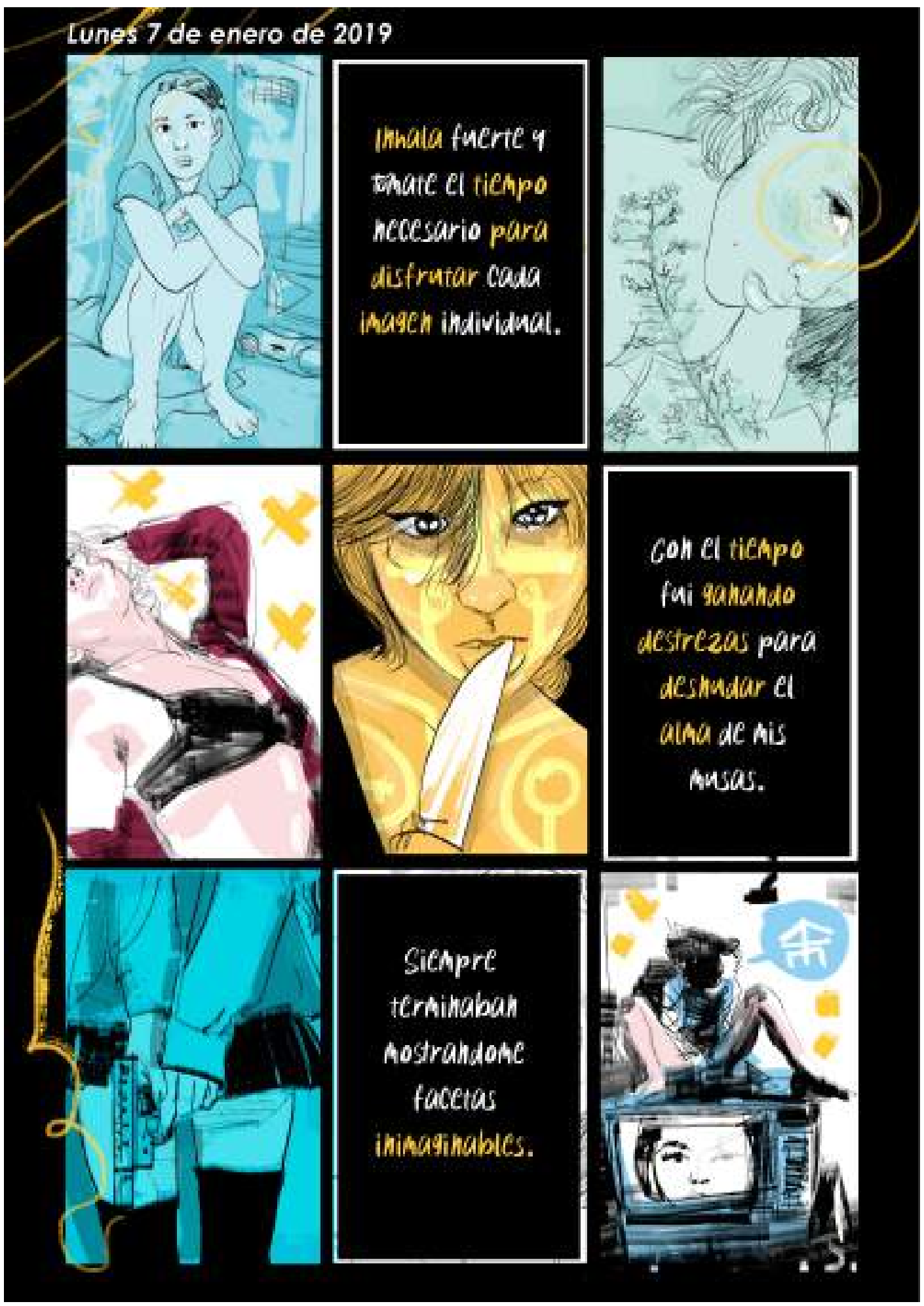


ANDRÉ

\section{SAL Y ROSAS}

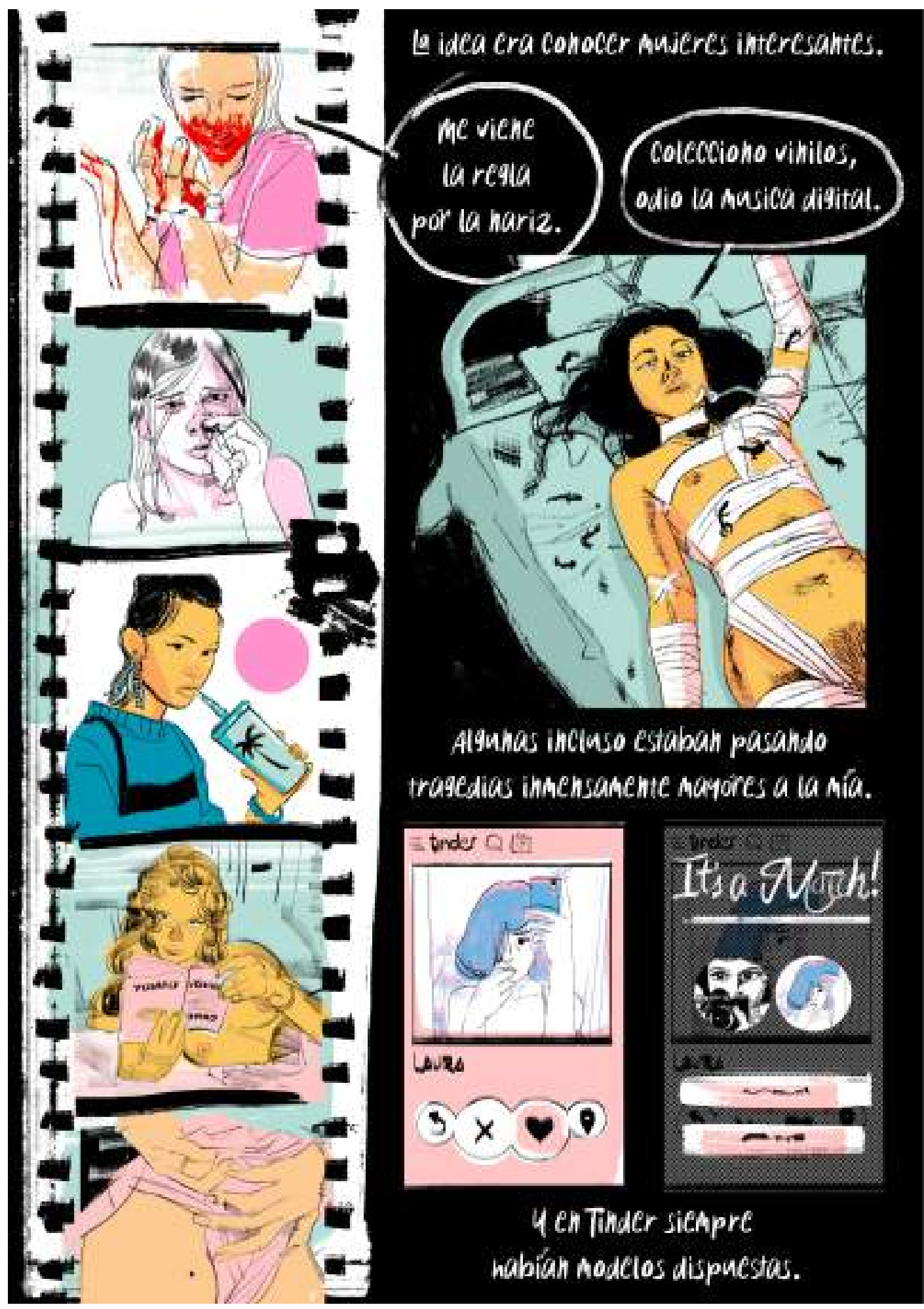


ANDRÉ

\section{SAL Y ROSAS}
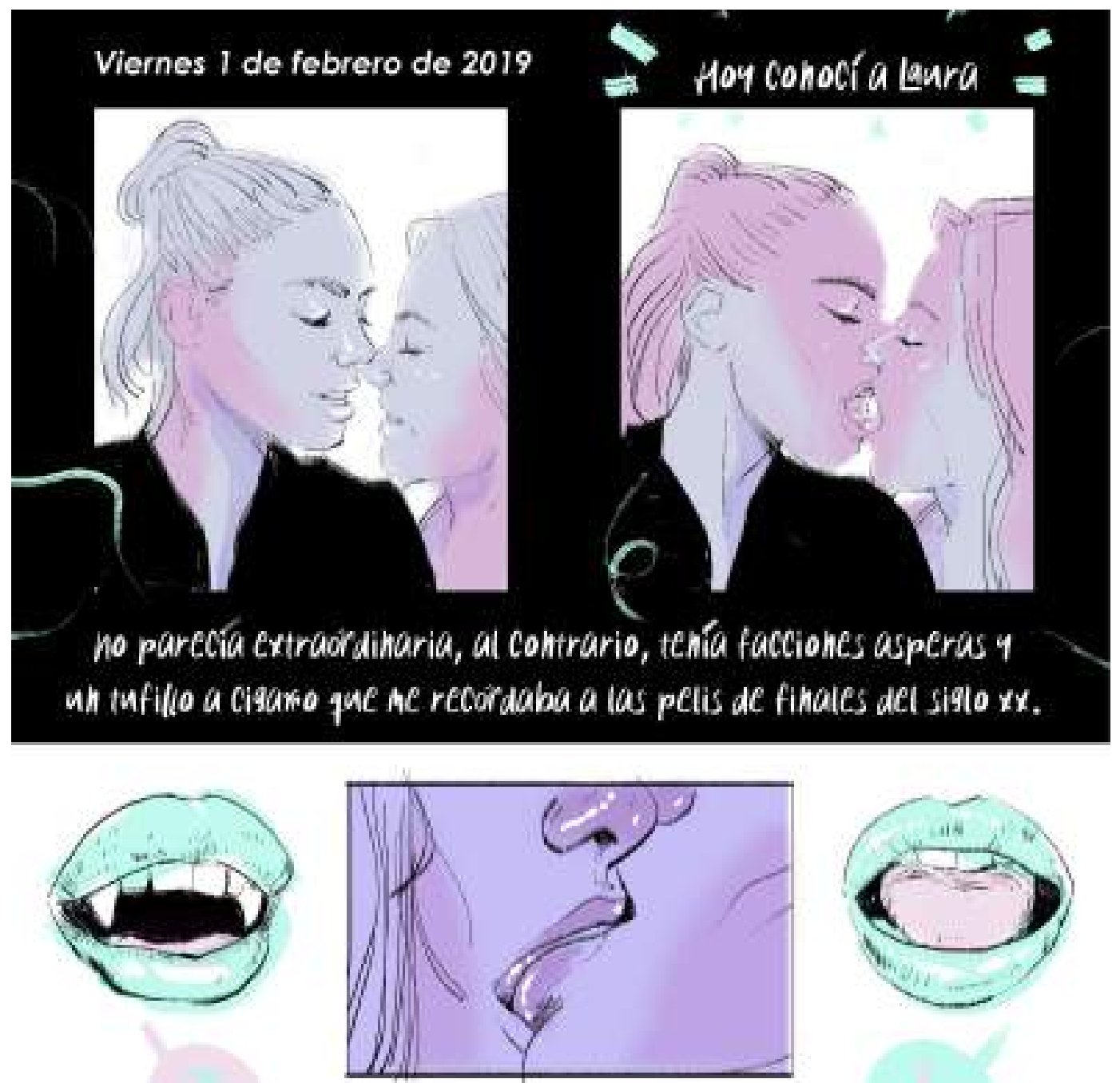

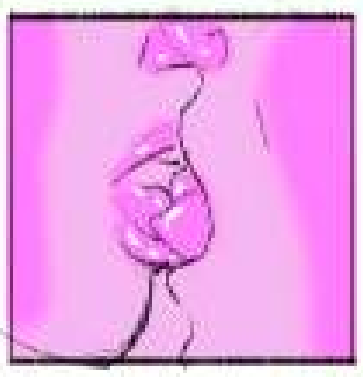

obvianente

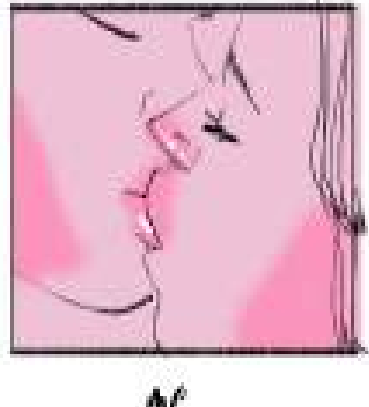

$M C$

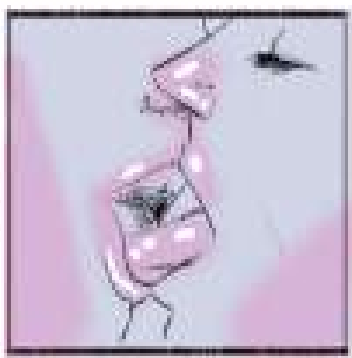

encante 


\section{SAL Y ROSAS}

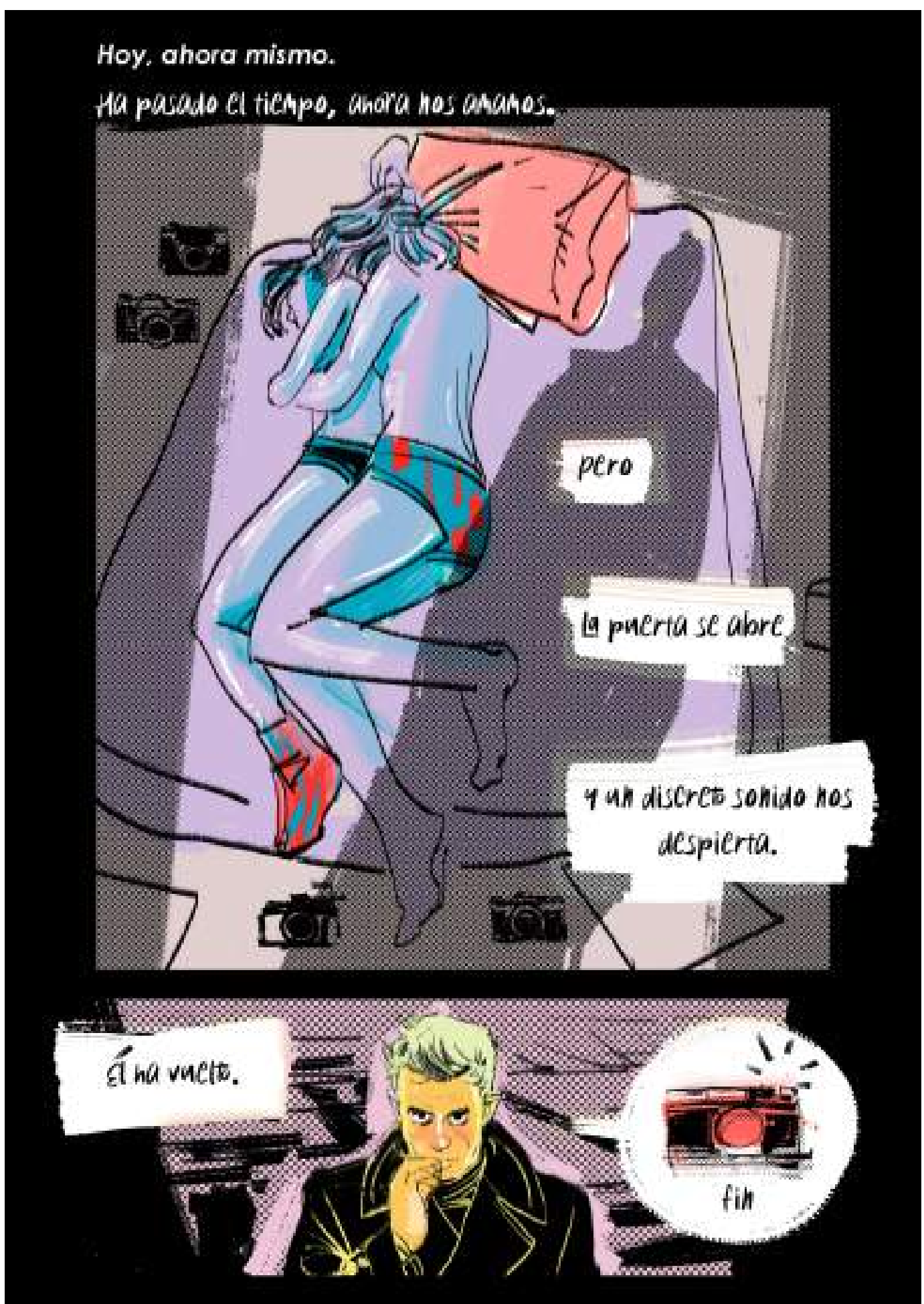

